Article

\title{
Using Genetic Algorithms to Develop a Dynamic Guaranteed Option Hedge System
}

\author{
Hyounggun Song ${ }^{1}$, Sung Kwon Han ${ }^{1}$, Seung Hwan Jeong ${ }^{1}$, Hee Soo Lee ${ }^{2}$ \\ and Kyong Joo Oh $1, *$ iD \\ 1 Department of Industrial Engineering, Yonsei University, 50 Yonsei-ro, Seodaemun-gu, Seoul 03722, Korea \\ 2 Department of Business Administration, Sejong University, 209 Neungdong-ro, Gwangjin-gu, \\ Seoul 03722, Korea \\ * Correspondence: johanoh@yonsei.ac.kr; Tel.: +82-2-2123-5720
}

Received: 11 June 2019; Accepted: 27 July 2019; Published: 29 July 2019

\begin{abstract}
In this research, we develop a guaranteed option hedge system to protect against capital market risks using a genetic algorithm (GA). We test the hedge effectiveness of our guaranteed option hedge strategy by comparing the performance of our system with those of other strategies. A genetic algorithm heuristic trading method for the optimization of a non-linear problem is applied to each system to improve the hedge effectiveness. The GA dynamic hedge system developed in this research is found to improve hedge effectiveness by reducing the option value volatility and increasing the total profit. Insurance companies are able to make more efficient investment strategies by using our guaranteed option hedge system. It contributes to the investment efficiency of the insurance companies and helps to achieve efficiency for financial markets. In addition, it helps to achieve sustained economic benefits to policyholders. In this sense, the system developed in this paper plays a role in sustaining economic growth.
\end{abstract}

Keywords: guaranteed option hedge; hedge effectiveness; genetic algorithm; variable annuity; dynamic hedge system

\section{Introduction}

Variable annuity is an insurance policy with an investment component. Some portions of the premium paid by the policyholder are invested in funds, and the benefit to the policyholder varies depending on the investment outcomes. Most variable annuity is issued with a minimum guaranteed option to protect the policyholder in cases of fund losses. Due to the global financial crisis of 2007, many insurance companies that handle variable annuity have suffered from huge losses in imbedded guaranteed options. This change was due to the significant decrease in share prices and increase in the interest rate, resulting in profit loss for funds that invest in stocks and bonds as underlying assets. However, some insurance companies with hedge systems were able to reduce or prevent losses during the crisis via hedge trading. Thus, many investment managers advise that hedging is an essential strategy to protect a portfolio from an unexpected market decline. Previous studies on hedging strategies for insurance management include hedging the guaranteed options embedded in guaranteed minimum benefits [1,2], hedging the guaranteed options under jumps and volatility risk [3], hedging single premium segregated fund contracts [4], and hedging strategies for unit-linked life insurance contracts [5].

Among the insurance companies that have established a hedge system, some companies have been successful with hedging, and some have failed, even though they have executed their hedge strategy $[2,3,5]$. To our knowledge, two important factors to consider for a successful hedge are the costs and risks: the transaction costs and costs of managing and monitoring the hedge position, 
and the risks of imperfect hedges resulting from sub-optimal hedge ratios, specification risks, basis risk, and volatility risk. Insurance companies should evaluate the impact of these costs and risks on investment profits and determine a strategy that maximizes the effectiveness of the hedge.

The purpose of this study is to develop a guaranteed option hedge system against capital market risks using a genetic algorithm (GA) and to test the effectiveness of the hedge strategy [6-8]. We apply a GA heuristic trading method for the optimization of a non-linear problem in each system to improve the hedge effectiveness. We compare the results from our hedge strategy with those from other strategies [9]. For an empirical study, we use variable annuity with a guaranteed lifetime withdrawal benefit (GLWB) contract and generate the cash flow of the contract using Monte Carlo simulation [10]. We estimate the delta and rho hedge ratios using the GA hedge strategy, non-GA hedge strategy, and no hedge strategy and compare the performance of the portfolio for these three strategies. Our empirical results show that the GA dynamic hedge system developed in this study improves hedge effectiveness by reducing the option value volatility and increasing the total profit.

A number of models or techniques have been developed for effective risk hedging against financial market risks. An effective risk hedging strategy helps investors to achieve efficient investments as well as achieving efficient financial markets, which is well known to play an important role in sustaining economic growth. Insurance companies are able to make more efficient investment strategies by using our guaranteed option hedge system. It contributes to the investment efficiency of the insurance companies and helps to achieve efficient financial markets. In addition, it helps to achieve sustained economic benefits to policyholders. In this sense, the system developed in this paper plays a role in sustaining economic growth.

The rest of the study is organized as follows. Section 2 describes variable annuity, guaranteed options, and hedge effectiveness. Section 3 is devoted to dynamic hedge system construction based on the GA. Section 4 tests the GA-dynamic hedge system using empirical data, and concluding remarks are presented in Section 5 .

\section{Description of Variable Annuity, Guaranteed Options, and Hedge Effectiveness}

\subsection{Variable Annuity}

Variable annuity or variable universal life insurance (VUL) is a type of life insurance that builds a cash value from separate accounts comprised of various instruments and investment funds, such as stocks, bonds, equity funds, money market funds, and bond funds. In variable annuity, the choice of the instruments and investment funds used for the separate accounts is entirely up to the contract owner. The 'variable' component in the name refers to a variable outcome in separate accounts whose values depend on the market conditions. The 'universal' component in the name refers to the flexibility the owner has in making the premium payments. The premiums can vary from nothing in a given month up to a maximum defined by the internal revenue code for the insurance. This flexibility of premium payments is in contrast to the fixed premium payments of whole life insurance.

Variable annuity is a type of permanent life insurance because the death benefit will be paid when the insured party dies. Most variable annuities have no endowment age (the age when the cash value equals the death benefit amount, which is typically 100 for whole life insurance) with a continually increasing death benefit, which is an advantage of variable annuity over whole life insurance. With a typical whole life insurance policy, the death benefit is limited to the face amount specified in the policy. In addition, if the separate accounts of variable annuity outperform the general accounts of the insurance company, variable annuity can generate a higher return than whole life insurance, which generates a fixed return. Therefore, a variable annuity policy can provide a higher value than a whole life insurance policy to the owner or beneficiary who pays the same amount. 


\subsection{Guaranteed Option}

Insurance companies often include very long-term guaranteed options in their products, which, in some circumstances, could turn out to be very valuable. Historically, these options, which are issued deeply out of the money, have been viewed by some insurers as having a negligible value [11-14]. However, a long-term guaranteed option with a term of 30 to 40 years has played an important role because insurance products have faced significant fluctuations in economic variables. The guaranteed options have been found to have a significant role in risk management for several insurance companies. Bolton et al. [15] described the origin and nature of these guarantees. They discussed the factors that have caused the importance of guaranteed options to increase dramatically in recent years. These factors include a decline in long-term interest rates and an increase in the mortality of various assets.

Variable annuity with a GLWB option allows the policyholder to withdraw a certain percentage of the single premium annually and offers a lifelong guarantee. Even if the fund value drops to zero, the insured can annually request a portion of the premium paid while he/she is alive. The maximum amount to be withdrawn is specified, but the total amount is not limited. Any remaining account fund at the time of the insured party's death is paid to the beneficiary as a death benefit. The insurer charges a fee for this guarantee, which is usually a pre-specified annual percentage of the account value [16].

\subsection{Methods of Testing Hedge Effectiveness}

Hedge effectiveness is an indicator that evaluates how efficient the hedging instruments are in protecting the fair value of a hedged asset. In particular, in cases where effectiveness is acknowledged in terms of accounting, objective criteria for effectiveness metrics are defined preliminarily, and differential acknowledgments are given according to the measured results. To evaluate different aspects of hedge effectiveness, various methodologies have been studied, including the following methods.

\subsubsection{The dollar-offset method}

The dollar-offset method, which has some historical significance in the accounting profession [17], compares changes in the fair value or cash flow of the hedged item and the derivative used for the hedge. The method can be applied either period-by-period or cumulatively. For a perfect hedge, the change in the value of the derivative exactly offsets the change in the value of the hedged item, and the negative of their ratio is 1.00, as shown in Equation (1).

$$
-\left(\sum_{i=1}^{n} X_{i} / \sum_{i=1}^{n} Y_{i}\right)=1.0
$$

where $\sum_{i=1}^{n} X_{i}$ is the cumulative sum of the periodic changes in the value of the derivative and $\sum_{i=1}^{n} Y_{i}$ is the cumulative sum of the periodic changes in the value of the hedged item. The minus sign in front of the ratio adjusts for the numerator and denominator being opposite in sign in a hedging relationship.

Of course, perfection is not necessary to qualify for hedge accounting. In a speech at the Securities and Exchanges Commission (SEC)'s 1995 Annual Accounting Conference, a member of the SEC's Office of the Chief Accountant articulated an 80/125 standard for hedge effectiveness as measured by the dollar-offset method [18]. This became a guideline for assessing the hedge effectiveness of futures contracts under the Statement of Financial Accounting Standards (SFAS) 80, and it carried over to testing the effectiveness of hedges under SFAS 133. The 80/125 standard requires that the derivative's change in value offset at least $80 \%$ and not more than $125 \%$ of the change in value of the hedged item. The formal expression of the test is presented in Equation (2).

$$
0.8 \leq-\left(\sum_{i=1}^{n} X_{i} / \sum_{i=1}^{n} Y_{i}\right) \leq 1.25
$$


Anyone who chooses to use this test should be aware that some researchers question its reliability [5,19-21]. The essential problem is that this ratio test is very sensitive to small changes in the value of the hedged item or the derivative.

\subsubsection{Variability-Reduction Method}

The variable reduction (VR) method assumes that the size of the risk-minimizing derivative is equal to that of the hedged item and that the position is opposite that of the hedged item. We call this method the one-to-one hedge. The variability-reduction method is closely related to the regression method, which allows a more effective hedge based on a statistical estimate of the risk-minimizing hedge ratio.

If a one-to-one hedge performs perfectly, the change in the value of the derivative exactly offsets the change in the value of the hedged item, i.e., $X_{i}+Y_{i}=0$ where $X_{i}$ is the change in the value of the derivative at time $i$ and $Y_{i}$ is a change in the value of the hedged item at time $i$. The variability reduction method compares the variability of the fair value or cash flow of the hedged (combined) position consisting of the hedged item and the derivative for the hedged item. This method places a greater weight on the larger deviations than the smaller ones by using the squared changes in value to measure ineffectiveness. The test statistic for this method is presented in Equation (3).

$$
\mathrm{VR}=1-\frac{\sum_{i=1}^{n}\left(X_{i}+Y_{i}\right)^{2}}{\sum_{i=1}^{n} Y_{i}^{2}}
$$

We use the mean-squared deviation from zero rather than the variance in (3) because the variance ignores certain types of ineffectiveness. For example, suppose that the change in the value of the hedged position is always $-\$ 0.20$, i.e., $D_{i}=X_{i}+Y_{i}=-\$ 0.20$ for every $i$, which implies that the offset is not perfect. If we use the variance of $D_{i}$ in the numerator, the test statistic is 1.0, implying a perfect hedge because $D_{i}=-\$ 0.20$ in every period and the calculated variance is zero. Lipe [22] suggests the standard critical value of the VR of hedge effectiveness is $80 \%$.

\subsubsection{Regression Method}

The regression method measures hedge effectiveness based on the adjusted $R^{2}$ produced by a regression model in which the change in the value of the hedged item $\left(Y_{i}\right)$ is the dependent variable and the change in the value of the derivative $\left(X_{i}\right)$ is the independent variable.

$$
Y_{i}=\hat{a}+\hat{b} X_{i}+e_{i}
$$

where $\hat{a}$ is the estimated intercept term, $\hat{b}$ is the estimated slope coefficient, and $e_{i}$ is the error term. Ederington [23] shows that the estimated slope coefficient is the variance-minimizing hedge ratio. Given our definitions of $X$ and $Y$, the slope of this Regression (4) should be negative and close to -1.0 for a perfect hedge. In terms of the hedge effectiveness test, a hedge ratio of the regression slope coefficient $(\hat{b})$ is found to be highly effective if the adjusted $R^{2}$ is greater than $80 \%$ [22].

\section{Proposed Model: GA Dynamic Hedge System}

In this section, the GA-dynamic guaranteed option hedge system procedure is described. Our hedge system consists of three phases: a data module construction, a valuation module construction, and an optimizing hedge ratio. The overall structure of the GA-dynamic hedge system is presented in Figure 1. 


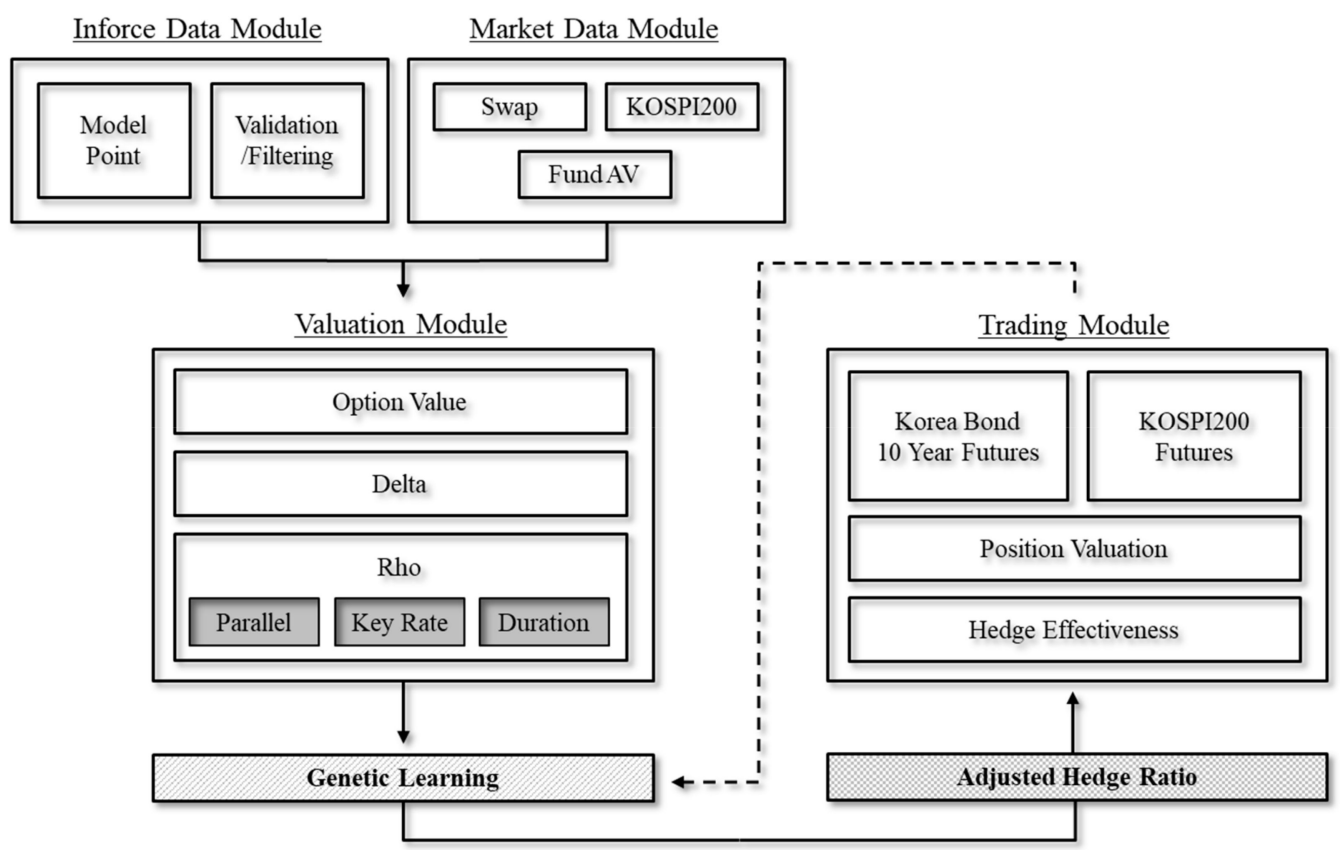

Figure 1. The overall structure of the GA-dynamic hedge system.

\subsection{Phase 1: Data Module Construction}

In this phase, a complete data module consists of an inforce data module and a market data module. The inforce data module has two parts: the model point and validation/filtering parts. The model point part includes the actuarial information such as the age, gender, insurance fee, and premium payment period. The validation/filtering part includes the information related to data error validation, and this part is synchronized with the SQL server. During this process, the logical flaws in the actuarial information are searched for, and they are modified when found. The market data module is classified into three parts: the swap, KOSPI200, and fund AV (account value) parts. The swap data include the daily closing price of the Korean Won (KRW) on-shore interest rate swap, which is an agreement between two counterparties to exchange cash flows (fixed vs. floating) of the same currency using the Bloomberg terminal. The KOSPI200 data include the daily closing price of the KOSPI200 index, and the fund $\mathrm{AV}$ of each contract is extracted at this part. The data module construction process is shown in Figure 2.

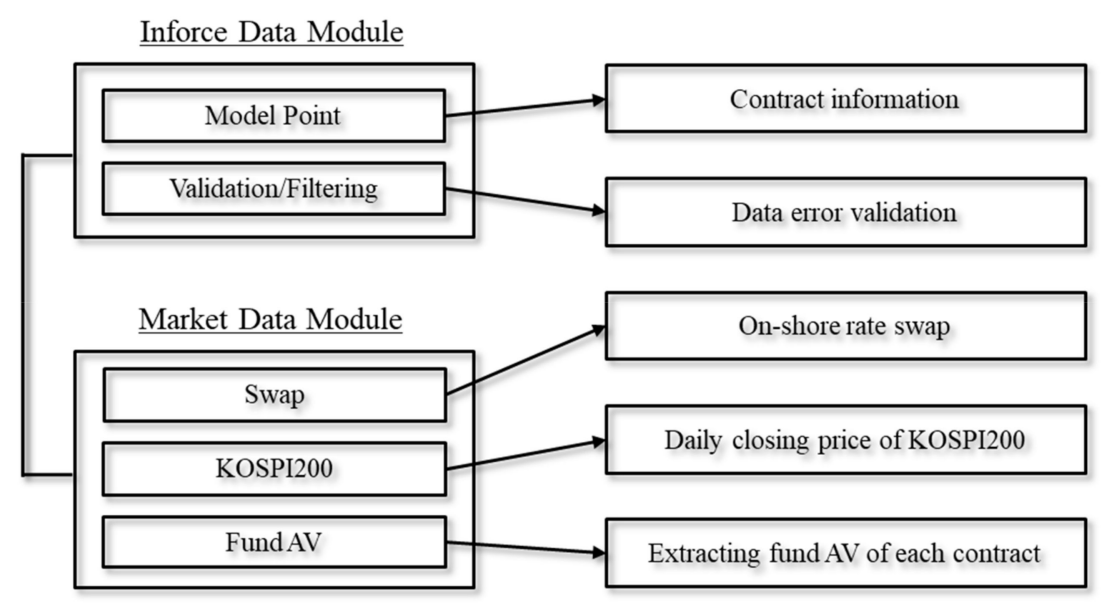

Figure 2. The data module construction process. 


\subsection{Phase 2: The Valuation Module Construction}

The valuation module includes various factors for hedge trading, such as the option value, delta, and rho. The option value is the present value (PV) of the guaranteed option, and it is calculated by subtracting the PV of the premium from the PV of the claim. The delta indicates the sensitivity of the option value to stock prices. In other words, the delta is the ratio of the change in the option value to the change in the price of the KOSPI200 index. For example, a delta of 0.7 indicates that for every $1 \%$ increase in the KOSPI200 index, the option value will increase by $0.7 \%$. The rho represents the sensitivity of the option value to interest rates. The valuation module construction process is displayed in Figure 3.

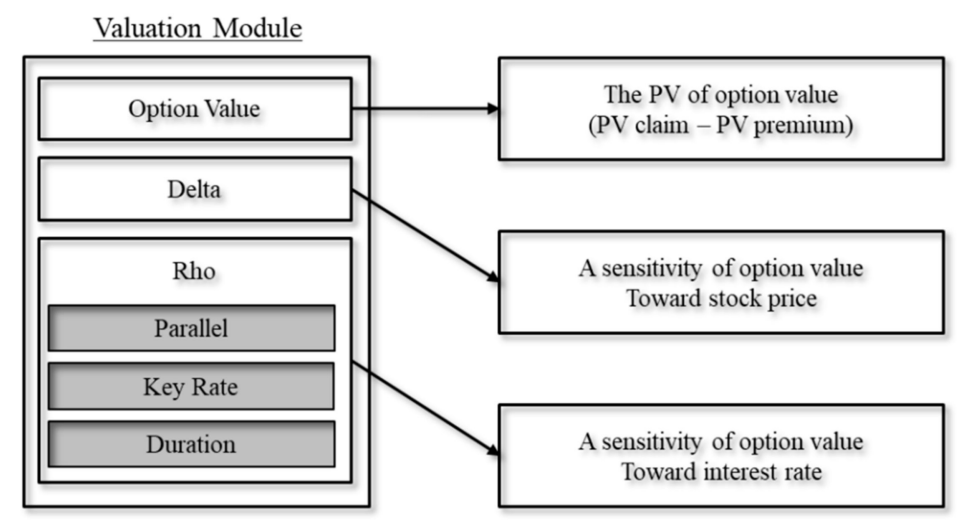

Figure 3. The valuation module construction process.

\subsection{Phase 3: Optimizing the Hedge Ratio}

In this phase, the optimized hedge ratio is estimated by a GA. The hedge ratio is the value of the position of the hedged assets relative to the value of the entire position, and shows how the assets are exposed to risk. In this study, a GA is used to optimize the hedge ratio for variable annuity. The hedge ratio set of each contract is treated as a chromosome which encodes a binary string, and the maximization of the profit from the hedge position is used as an objective function. Each hedge ratio is a gene in a chromosome, and only the chromosomes which are in the top $10 \%$ of fitness are survived. Among the other $90 \%$ of chromosomes, random selection and single point crossover techniques are used. After the crossover process, some genes of the chromosomes are mutated to random genes based on a mutation rate. Finally, the next generation is composed with the highest $10 \%$ of the chromosomes of the previous generation and the chromosomes from selection, crossover, and mutation. The GA stops when the fitness value has not improved by at least $0.01 \%$ during the last 2000 trials. In this paper, a GA is used to determine an appropriate hedge ratio with a population size, crossover rate, and mutation rate of 2000, 0.5, and 0.06, respectively. The larger the population and generation, the more likely it is to obtain a globally optimized solution, but the level of complexity increases exponentially in finding an optimal hedge ratio. Therefore, the empirical analysis is usually carried out using a reasonable stopping condition in the process of finding an optimal solution.

In this study, we employ two hedge ratios, that is, the delta hedge ratio and the rho hedge ratio. To optimize the hedge ratio, the profit from the hedge position is set as the fitness function (or objective function) of the GA as follows:

$$
\text { Profit from the hedge position }=\sum_{i=1}^{n} H_{i} / \sum_{i=1}^{n} G O_{i}
$$

where $H_{t}=D_{t}+R_{t}, H_{t}$ is the profit of the hedge trading at time $t, D_{t}$ is the profit from delta hedge trading, $R_{t}$ is the profit from rho hedge trading, and $G O_{i}$ is the guaranteed option value at time $t$. The delta and rho hedge ratios are used as investment weights on the KOSPI200 futures and Korea bond 10-year futures, respectively. We apply a genetic algorithm heuristic trading method for the 
optimization of a non-linear problem for each system to improve the hedge effectiveness. The hedge ratio optimization process is shown in Figure 4.

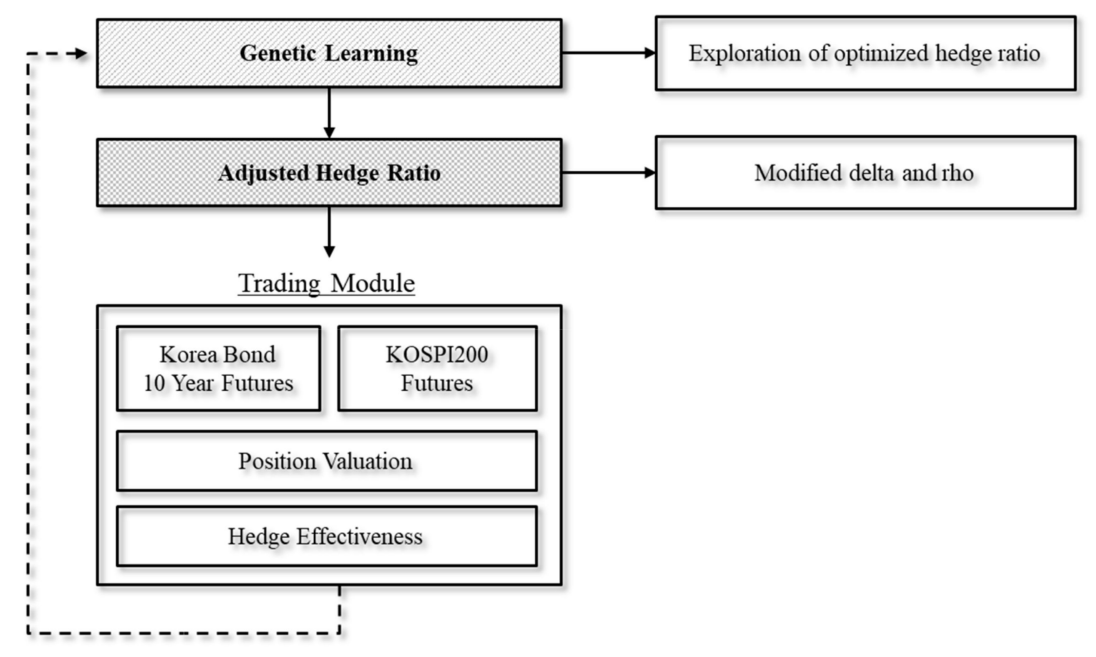

Figure 4. A process of optimizing the hedge ratio.

\section{The Empirical Study}

\subsection{The Simulation Study}

The valuation and hedging of the various provisions embedded in VUL contracts is a challenging exercise because the involved options are long-term, path-dependent, and complex. Investors can be modelled as facing a non-trivial optimal stochastic impulse control problem when determining their withdrawal strategies for GLWB contracts. A variety of contractual features, as well as some alternative assumptions about the policyholder's behavior, should be considered. In this study, geometric Brownian motion (GBM) is used as the stochastic setting, and Monte Carlo methods are used to show the effects of a variety of contractual provisions, assuming that the policyholder follows a particular strategy, such as making no withdrawals during a specified number of years.

\subsubsection{Risk Neutral Simulation}

For the simulation, we assume a risk-neutral world with the following methodological conditions. First, we assume that the expected return of the selected fund is equal to each asset scenario's return. We use the KOSPI200 index for the equity return and the 3-year Korean government bond for the bond return in this study. Second, the expected payoff is calculated from the product structure at maturity. Finally, we discount the expected payoff at the risk-free rate to obtain the present value of the guaranteed option. The risk-free rate is defined as the market value at each valuation time.

\subsubsection{The Scenario Model}

We assume that the process of the underlying asset in a risk-neutral world is as follows:

$$
d S=\mu S d t+\sigma S d z
$$

where $d z$ is a Wiener process, $S$ is the price of asset, $\mu$ is the expected return in a risk-neutral world, and $\sigma$ is the volatility of the underlying asset. To simulate the path followed by $S$, we can divide the life of the asset into $N$ short intervals of length $\Delta t$; the approximation of (6) is presented in Equation (7).

$$
S(t+\delta t)-S(t)=\mu S(t) \delta t+\sigma S(t) \varepsilon \sqrt{\delta t}, \quad \varepsilon \sim N(0,1)
$$


A log-normal model is applied to generate the asset return scenario. To incorporate the cash flow from the asset, the discrete version of $S$ is used as follows:

$$
\ln \frac{S_{t+\delta t}}{S_{t}}=\left(\mu-\frac{\sigma^{2}}{2}\right) \delta t+\delta \varepsilon \sqrt{\delta t}
$$

This model is applied to the equity and bond fund return scenarios. The parameter is derived from the 75th percentiles of the annualized moving standard deviation of the KOSPI200 index and the moving standard deviation of the 3-year Korean government bond index from 10-years of historical data.

\subsubsection{Product Specification}

In this study, we focus exclusively on GLWBs. We construct a general GLWB single product that guarantees a lifetime withdrawal benefit. A variable annuity with a GLWB has become the most popular form of annuity, as retirees seek income protection and equity market participation. The holder of the contract is allowed to withdraw a specified percentage of the guaranteed base benefit each year of the insured's life, even if the actual account value decreases to zero due to the annual guaranteed withdrawal or market declines. The base benefit is typically set to the contract value at the time the VUL is purchased and is generally reset at varying intervals, usually each year, based on the performance of the underlying portfolios. The guarantees provided by a GLWB can provide confidence to the insured that they will have a guaranteed income for life, regardless of how long they live or what direction the market takes.

\subsection{Empirical Study with the GA-Dynamic Hedge System}

\subsubsection{Experimental Setting}

In this study, a Monte Carlo simulation is performed using 1000 scenarios based on the daily data of 2000 variable annuity contracts. The experimental period is from 2 May 2011 to 30 September 2013. The option price and the delta and rho option sensitivities are used for trading.

\subsubsection{Assumptions for the Empirical Study}

According to the main assumption of a risk neutral world, the option price is equal to the expected value of the payoff with respect to a risk-neutral probability measure. Moreover, the option can be theoretically replicated by the underlying assets with dynamic hedging. The number of shares of the underlying asset held in a dynamic hedging strategy is determined using the sensitivities (delta and rho) of the option value to the underlying asset.

As an insurance company can diversify away its mortality risk by selling enough policies, we assume that the mortality risk can be diversified away. Moller [5] investigates the pricing and hedging of insurance contracts under mortality risk. We assume that the account value that determines the benefit level is linked to a market index, such as the KOSPI200 and 3-year Korean government bonds. The product used consists of three local funds, and they are selected from policyholders with a range from $0 \%$ to $100 \%$. Table 1 shows the information for the three funds.

Table 1. Fund information.

\begin{tabular}{cccccc}
\hline Fund & $\begin{array}{c}\text { Initial } \\
\text { Investment }\end{array}$ & $\begin{array}{c}\text { Proportion } \\
\text { of Equity }\end{array}$ & $\begin{array}{c}\text { Proportion } \\
\text { of Bonds }\end{array}$ & Benchmark Index & $\begin{array}{c}\text { Management } \\
\text { Fee }\end{array}$ \\
\hline Korean Bond & May 2011 & - & 1.0000 & $\begin{array}{c}3 \text { Year Korean } \\
\text { Government Bond }\end{array}$ & $0.40 \%$ \\
Korean Index Equity & May 2011 & 0.9232 & 0.0768 & KOSPI200 & $0.60 \%$ \\
Korean Active Equity & May 2011 & 0.8438 & 0.1562 & KOSPI & $0.70 \%$ \\
\hline
\end{tabular}

(Data source: Korea Life Insurance Association). 


\subsubsection{Experimental Results}

Delta measures the sensitivity of the option value to the underlying asset. The risk associated with GLWB products due to equity movement is measured by delta for the KOSPI200 index futures. Rho measures the sensitivity of an option value to a change in the interest rate. The risk associated with GLWB products due to interest rate movement is measured by rho with respect to 10-year on-shore interest rate swaps (IRS). The Korean government bond (KGB) futures with a 10-year maturity can be used together with the 10-year IRS if the liquidity of the 10-year KGB futures is high and the transaction cost is lower than that of the10-year IRS. For hedge trading, we calculate the delta and rho hedge ratio using Bloomberg terminal. For the GA hedge method, Table 2 reports the values of the delta hedge positions in KRW with the option values across a wide range of percentage changes in the KOSPI 200 index futures, and Table 3 reports the values of the rho hedge positions in KRW with the option values across a range of percentage changes in the 10-year IRS.

Table 2. The option and delta hedge position values.

\begin{tabular}{ccc}
\hline $\begin{array}{c}\text { \% Change in the } \\
\text { KOSPI200 Index Futures }\end{array}$ & $\begin{array}{c}\text { Option Value } \\
\text { (KRW) }\end{array}$ & $\begin{array}{c}\text { Value of the Delta Hedge Position } \\
\text { (KRW) }\end{array}$ \\
\hline $10 \%$ & $483,057,234$ & $3,600,114$ \\
$9 \%$ & $486,588,492$ & $3,781,592$ \\
$8 \%$ & $490,620,418$ & $3,904,631$ \\
$7 \%$ & $494,397,753$ & $3,676,949$ \\
$6 \%$ & $497,974,315$ & $3,857,414$ \\
$5 \%$ & $502,112,580$ & $4,188,485$ \\
$4 \%$ & $506,351,284$ & $3,863,599$ \\
$3 \%$ & $509,839,777$ & $3,763,738$ \\
$2 \%$ & $513,878,759$ & $4,136,469$ \\
$1 \%$ & $518,112,714$ & $4,104,580$ \\
$0 \%$ & $522,087,919$ & $4,041,269$ \\
$-1 \%$ & $526,195,252$ & $4,039,689$ \\
$-2 \%$ & $530,167,296$ & $4,141,470$ \\
$-3 \%$ & $534,478,192$ & $4,139,081$ \\
$-4 \%$ & $538,445,458$ & $4,064,585$ \\
$-5 \%$ & $542,607,362$ & $4,276,658$ \\
$-6 \%$ & $546,998,774$ & $4,339,338$ \\
$-7 \%$ & $551,286,037$ & $4,304,274$ \\
$-8 \%$ & $555,607,321$ & $4,419,148$ \\
$-9 \%$ & $560,124,333$ & $4,389,692$ \\
$-10 \%$ & $564,386,704$ & $4,431,821$ \\
\hline & & \\
\hline
\end{tabular}

Table 3. Option and rho hedge position values.

\begin{tabular}{ccc}
\hline \% Change in 10-Year IRS & $\begin{array}{c}\text { Option Value } \\
\text { (KRW) }\end{array}$ & $\begin{array}{c}\text { Value of Rho Hedge Position } \\
\text { (KRW) }\end{array}$ \\
\hline $0.50 \%$ & $165,553,400$ & $3,600,114$ \\
$0.10 \%$ & $440,919,394$ & $3,781,592$ \\
$0.00 \%$ & $522,087,919$ & $3,904,631$ \\
$-0.10 \%$ & $609,638,460$ & $3,676,949$ \\
$-0.50 \%$ & $1,026,702,445$ & $3,857,414$ \\
\hline
\end{tabular}

We also conducted the same experiment using the non-GA hedge method to compare the hedge effectiveness of the GA and non-GA hedge methods. For the non-GA method, the numbers of delta and rho hedge contracts are obtained using the GLWB delta and rho values, respectively. The delta of a GLWB is the ratio of the changes in GLWB value to the changes in the KOSPI200 index futures value, and the rho of a GLWB is the ratio of the changes in the GLWB value to the changes in the 10-year IRS value. Table 4 shows the hedge effectiveness of the non-GA and GA hedge strategies measured by the 
dollar-offset, variability-reduction, and regression methods. The effectiveness measurement of the dollar-offset and variability reduction shows slight increase in effectiveness of the GA hedge strategy by $0.32 \%$ and $0.69 \%$, respectively. According to the regression method, the effectiveness of the GA hedge strategy is found to increase significantly, i.e., by $4.22 \%$. Therefore, the three measurements of hedge effectiveness show that the hedge effectiveness of the GA hedge strategy is superior to that of the non-GA hedge strategy.

Table 4. Hedge effectiveness of the Non-GA and GA hedge strategies.

\begin{tabular}{cccc}
\hline & Dollar Offset & Variability Reduction & Regression \\
\hline Non-GA hedge & $105.57 \%$ & $97.79 \%$ & $92.40 \%$ \\
GA hedge & $105.89 \%$ & $98.48 \%$ & $96.62 \%$ \\
Difference in Effectiveness & $0.32 \%$ & $0.69 \%$ & $4.22 \%$ \\
\hline
\end{tabular}

In addition, we compare the performance of the GA hedge strategy, non-GA hedge strategy, and no hedge strategy. Table 5 reports the increase in the option value, profit by the hedge strategy, and volatility of the option value generated by the three strategies and shows the superiority of the GA hedge strategy. In the case of the no hedge strategy scenario, the guaranteed option value increased by 11,031.9 thousand KRW during the sample period. Alternatively, the non-GA and GA strategies generated gross profits of 685.5 thousand KRW and 1421.9 thousand KRW, respectively, which indicates successful hedging by the GA strategy. Moreover, the daily option value volatility decreased from 6035.3 thousand KRW without a hedge strategy to 858.8 thousand KRW with the GA hedge strategy.

Table 5. Comparison of strategy performance.

\begin{tabular}{cccc}
\hline & $\begin{array}{c}\text { Increase in the Option Value } \\
(\text { KRW'000') }\end{array}$ & $\begin{array}{c}\text { Profit from Hedge } \\
\text { (KRW'000') }\end{array}$ & $\begin{array}{c}\text { Option Value Volatility } \\
\text { (KRW'000') }\end{array}$ \\
\hline No Hedge & $11,031.9$ & 0 & 6035.3 \\
Non-GA & $11,717.4$ & 685.5 & 896.2 \\
GA & $12,453.8$ & 1421.9 & 858.8 \\
\hline
\end{tabular}

\section{Concluding Remarks}

Hedging the options embedded in the guaranteed minimum benefits of variable annuity is difficult because it requires real-time analysis of massive amounts of long-term maturity contract data. Indeed, an insurance company must handle hundreds of thousands of guaranteed option valuations in a short period of time for a dynamic hedge. The Black-Sholes formula, which is widely used to value options, cannot reflect the complex structure of the actuarial cash flow.

The entire series of the cash flows from the variable annuity contract was produced through a Monte Carlo simulation to develop a dynamic hedge system. This study developed a dynamic hedge system that uses an inforce data module to build the contract data and verify the data errors, a market data module that processes the real-time market data, a valuation module that produces the guaranteed option price for each contract, the option variables through a sensitivity test, and a trading module that produces the trading position by matching the delta and rho values to the sensitivity of the derivatives. For a high-speed operation, the valuation module is realized with a high-performance computing (HPC) system to maximize the efficiency of data production.

The empirical results show that the hedge effectiveness of the GA hedge strategy is superior to that of the non-GA hedge strategy. The increase in the effectiveness of the GA hedge strategy measured by the dollar-offset, variability-reduction, and regression methods is $0.32 \%, 0.69 \%$, and $4.22 \%$, respectively. It is also found that compared to the no hedge strategy, the non-GA and GA strategies generated gross profits of 685.5 thousand KRW and 1421.9 thousand KRW, respectively. Moreover, the daily option value volatility decreased from 6035.3 thousand KRW without a hedge strategy to 858.8 thousand KRW with the GA hedge strategy. 
The main goal of hedging is to achieve perfect hedge effectiveness, which is an indicator of how well the hedge asset compensates the hedge subject. In this study, a GA is proposed to resolve the difficulties in finding the proper hedge ratios for the delta and rho hedges, and the algorithm performance is evaluated against that of other rule-based trading methods. The GA dynamic hedge system developed in this paper is found to improve hedge effectiveness by reducing the option value volatility and increasing the total profit.

This study has potential limitations. The model developed in this paper is based on Korean variable annuity contracts that hold portfolio of securities in Korean markets during the sample period. As such, the empirical results are limited to Korean market data traded in a specific time period. Based on our model, a future research can be enriched by developing a model that can be utilized for other variable annuity contracts containing various types of financial assets in a global market.

Author Contributions: Project Administrator, K.J.O.; Validation, S.K.H.; Formal Analysis, S.H.J.; Writing-Original Draft Preparation, H.G.S.; Writing-Review \& Editing, H.S.L.

Funding: This research received no external funding.

Conflicts of Interest: The authors declare no conflicts of interest.

\section{References}

1. Coleman, T.F.; Li, Y.; Patron, M.C. Total risk minimization using Monte Carlo simulations. In Handbooks in Operations Research and Management Science: Financial Engineering; Birge, J.R., Linetsky, V., Eds.; Elsevier: Amsterdam, The Netherlands, 2007; Volume 15, pp. 593-635.

2. Coleman, T.F.; Li, Y.; Patron, M.C. Hedging guarantees in variable annuities under both equity and interest rate risks. Insur. Math. Econ. 2006, 38, 215-228. [CrossRef]

3. Coleman, T.F.; Li, Y.; Patron, M. Robustly hedging variable annuities with guarantees under jump and volatility risks. J. Risk Insur. 2007, 74, 347-376. [CrossRef]

4. Hardy, M. Hedging and reserving for single-premium segregated fund contracts. N. Am. Actuar. J. 2000, 4, 63-74. [CrossRef]

5. Moller, T. Hedging equity-linked life insurance contracts. N. Am. Actuar. 2001, 5, 79-95. [CrossRef]

6. Ahn, J.J.; Byun, H.W.; Oh, K.J.; Kim, T.Y. Using ridge regression with genetic algorithm to enhance real estate appraisal forecasting. Expert Syst. Appl. 2012, 39, 8369-8379. [CrossRef]

7. Oh, K.J.; Kim, T.Y.; Min, S. Using genetic algorithm to support portfolio optimization for index fund management. Expert Syst. Appl. 2005, 28, 371-379. [CrossRef]

8. Ahn, J.J.; Lee, S.J.; Oh, K.J.; Kim, T.Y. Intelligent forecasting for financial time series subject to structural changes. Intell. Data Anal. 2009, 13, 151-163. [CrossRef]

9. Benartzi, S.; Thaler, R.H. Naive diversification strategies in defined contribution saving plans. Am. Econ. Rev. 2001, 91, 79-98. [CrossRef]

10. Glasserman, P. Monte Carlo Methods in Financial Engineering. In Stochastic Modelling and Applied Probability; Springer: Berlin/Heidelberg, Germany, 2003.

11. Benet, B.A.; Luft, C.F. Hedge performance of SPX index options and S \& P 500 futures. J. Futures Mark. 1995, 15, 619-717.

12. Black, F.; Scholes, M.S. The pricing of options and corporate liabilities. J. Political Econ. 1973, 81, 736-1653. [CrossRef]

13. Dempster, M.A.H.; Hutton, J.P. Pricing American stock options by linear programming. Math. Financ. 1999, 9, 229-254. [CrossRef]

14. Hull, J.C. Options, Futures, and Other Derivatives, 8th ed.; Pearson Education: New York, NY, USA, 2012.

15. Bolton, M.J.; Carr, D.H.; Collis, P.A.; George, C.M.; Knowles, V.P.; Whitehouse, A.J. Reserving for Annuity Guarantees-The Report of the Annuity Guarantees Working Party; Institute of Actuaries: London, UK, 1997.

16. Piscopo, G.; Haberman, S. The valuation of guaranteed lifelong withdrawal benefit options in variable annuity contract and the impact of mortality risk. N. Am. Actuar. 2011, 15, 59-76. [CrossRef]

17. Kawaller, I.G.; Koch, P.D. Meeting the 'Highly Effective Expectation' Criterion for Hedge Accounting. J. Deriv. 2000, 7, 79-87. [CrossRef] 
18. Swad, S.M. Accounting and Disclosures for Derivatives. In Proceedings of the Twenty-Second Annual National Conference on Current SEC Developments, Office of the Chief Accountant, US Securities and Exchange Commission, Washington, DC, USA, 10 January 1995.

19. Canabarro, E. A Note on the Assessment of Hedge Effectiveness Using the Dollar Offset Ratio Under FAS 133, Research Report; Goldman Sachs \& Co: New York, NY, USA, 1999.

20. Althoff, J.M.; Finnerty, J.D. Testing hedge effectiveness: SFAS No. 133 and the new derivatives accounting landscape. Inst. Investor 2001, 1, 44-51.

21. Finnerty, J.D.; Grant, D. Alternative approaches to testing hedge effectiveness under SFAS No. 133. Account. Horiz. 2002, 16, 95-108. [CrossRef]

22. Lipe, R.C. Current accounting projects. Presented at the Twenty-Fourth Annual National Conference on Current SEC Developments, Office of the Chief Accountant, US Securities and Exchange Commission, Washington, DC, USA, 11 December 1996.

23. Ederington, L.H. The hedging performance of the new futures markets. J. Financ. 1979, 34, 157-170. [CrossRef]

(C) 2019 by the authors. Licensee MDPI, Basel, Switzerland. This article is an open access article distributed under the terms and conditions of the Creative Commons Attribution (CC BY) license (http://creativecommons.org/licenses/by/4.0/). 